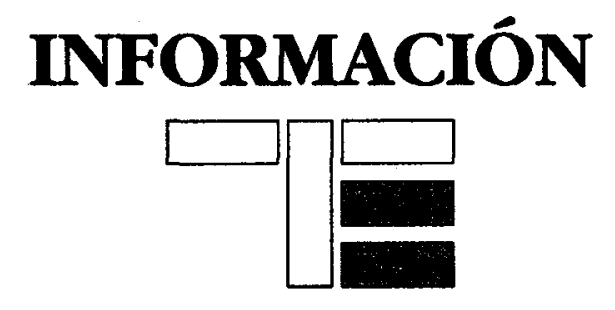





\title{
X CONGRESO INTERUNIVERSITARIO DE TEORÍA DE LA EDUCACIÓN
}

\author{
Nuevos espacios y nuevos entornos de educación
}

Alicante, 11 y 12 de abril de 2005

Los eventos científicos de Teoría de la Educación ya llevan unos veinte años de actividad ininterrumpida. En 1982 se celebra la reunión constitutiva del grupo de docentes universitarios en la Universidad de Murcia, en la que los catedráticos y adjuntos de Pedagogía General, Filosofía de la Educación y otras materias afines reflexionaron sobre el sentido y perspectivas futuras de la Teoría de la Educación. Se acuerda celebrar un Seminario Interuniversitario anual para coordinar los temas, metodología y demás aspectos heurísticos de este dominio científico: Teoría de la Educación. Así nace el Seminario Interuniversitario de Teoría de la Educación - SITE-, que cada año se desarrolla en una universidad española diferente y en el que convergemos los representantes más genuinos de cada Facultad.

Abriéndonos a la sociedad y a la historia, en concomitancia con las reflexiones de otros grupos de investigación análogos, el SITE considera sobre el sentido de la educación y sus elementos constituyentes, reflexionamos sobre las respuestas pertinentes a ofrecer ante las situaciones más relevantes, incisivas, innovadoras o críticas del sistema educativo. En este sentido el Seminario - SITE- elicitó otro evento que difundiera más nuestro esfuerzo intelectual. Así surge el Congreso Interuniversitario de Teoría de la Educación - CITE- Éste es un medio de incorporar a diversos profesionales, especialistas y estudiantes interesados en las respuestas a dar ante nuevos retos como la democracia, la innovación, la globalización, la interculturalidad, la indisciplina y violencia, etc.

El X CITE de este próximo 2005 debe interpretarse dentro de la complejidad sociocultural del momento presente. Efectivamente, junto al peso configurativo de las NNTTIC, convergen en la complejidad de la educación las situaciones de multiculturalidad, además de problemas críticos provenientes de las situaciones de educación informal (indisciplina y violencias, incorporados) además del peso creciente de la educación no-formal.

Por consiguiente, hay que pensar en dar nuevas soluciones, planteando nuevos espacios y la correspondiente optimización de los anteriores, además de definir nuevos parámetros de los entornos institucionales de aprendizaje.

Se entiende que es un evento con suficiente relevancia científica, cultural y social. Esto puede verificarse con el planteamiento y la consecución de los objetivos que nos hemos formulado. En este orden de ideas, hay una finalidad heuristica general que consiste en profundizar mediante el diálogo racional sobre los contenidos y paradigmas de la reflexión teorética de la educación. Esta pretensión se concreta en los siguientes objetivos específicos: 
a) Poner en común los avances y estado de la cuestión de la educación y los estudios del área de conocimientos de Teoría de la Educación.

b) Responder a las exigencias de la problemática actual de los diversos aspectos del sistema educativo.

c) Convocar a los interesados en Teoría de la Educación de las diferentes Universidades españolas, en sus modalidades de Escuelas de Magisterio, Facultades de Educación, Institutos de Ciencias de la Educación, Sociedades Científicas, Cuerpos Docentes (maestros, profesores, educadores, terapeutas, etc.) y de Asesoramiento (inspectores, psicopedagogos, etc.).

d) Informar de las conclusiones y proposiciones a las diferentes administraciones, sociedad, organismos, etc.

Salvador Peiró i Gregori Universidad de Alicante 